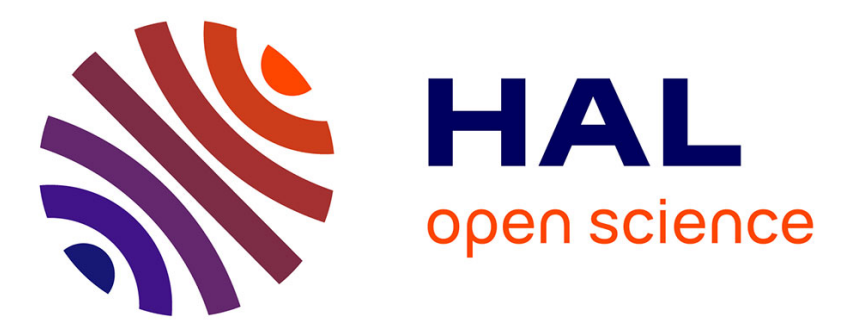

\title{
Polylactide films produced with bixin and acetyl tributyl citrate: Functional properties for active packaging
}

\author{
Liana Stoll, Sandra Domenek, Simone Hickmann Flôres, Sonia Marli B.
} Nachtigall, Alessandro de Oliveira Rios

\section{- To cite this version:}

Liana Stoll, Sandra Domenek, Simone Hickmann Flôres, Sonia Marli B. Nachtigall, Alessandro de Oliveira Rios. Polylactide films produced with bixin and acetyl tributyl citrate: Functional properties for active packaging. Journal of Applied Polymer Science, 2021, 138 (17), pp.50302. 10.1002/app.50302 . hal-03413495

HAL Id: hal-03413495

https://hal-agroparistech.archives-ouvertes.fr/hal-03413495

Submitted on 3 Nov 2021

HAL is a multi-disciplinary open access archive for the deposit and dissemination of scientific research documents, whether they are published or not. The documents may come from teaching and research institutions in France or abroad, or from public or private research centers.
L'archive ouverte pluridisciplinaire HAL, est destinée au dépôt et à la diffusion de documents scientifiques de niveau recherche, publiés ou non, émanant des établissements d'enseignement et de recherche français ou étrangers, des laboratoires publics ou privés. 


\title{
Polylactide films produced with bixin and acetyl tributyl citrate: Functional properties for active packaging
}

\author{
Liana Stoll $^{1}$ (1) | Sandra Domenek ${ }^{2}$ ( ) | Simone Hickmann Flôres ${ }^{1}$ | \\ Sonia Marli B. Nachtigall ${ }^{3}$ | Alessandro de Oliveira Rios ${ }^{1}$ ()
}

${ }^{1}$ Institute of Food Sciences and Technology, Federal University of Rio Grande do Sul (UFRGS), Porto Alegre, Brazil

${ }^{2}$ UMR SayFood, Université Paris-Saclay, INRAE, AgroParisTech, Massy, France

${ }^{3}$ Institute of Chemistry, Federal University of Rio Grande do Sul (UFRGS), Porto Alegre, Brazil

\section{Correspondence}

Sandra Domenek, UMR SayFood, Université Paris-Saclay, INRAE, AgroParisTech, Massy 91300, France. Email: sandra.domenek@agroparistech.fr

Funding information

Fundação de Amparo à Pesquisa do Estado do Rio Grande do Sul; Doctoral Program Sandwich Abroad - CAPES PDSE, Grant/Award Number: 88881.189021/2018-01

\begin{abstract}
Packaging materials are decisive to preserve the quality and nutritional value of food. Polylactide (PLA) is a biodegradable polymer with adequate mechanical properties for packaging applications, but its moderate oxygen barrier properties and high UV light transmission hamper its performance as packaging for oxygen- and light-sensitive products. Bixin, a carotenoid with coloring and antioxidant character, was used to improve the light barrier of PLA films plasticized or not with acetyl tri-butyl citrate (ATBC). The films were subjected to thermal treatment mimicking polymer processing temperatures. Despite more than $74 \mathrm{wt} \%$ of bixin degraded during heat treatment, films were still blocking up to $95 \%$ of UVA and $90 \%$ of UVB transmission. Plasticizing PLA with ATBC accelerated up to six times the bixin release into a food simulant, which allowed to reach relevant concentrations for food preservation. In conclusion, bixin is a promising natural antioxidant and UV-shielding additive of biodegradable packaging.
\end{abstract}

\section{K E Y W O R D S}

biodegradable, biopolymers, packaging, renewable polymers

\section{1 | INTRODUCTION}

The success of the food industry is highly dependent on the quality of the packaging materials used to wrap food products and food ingredients. The fundamental role of packaging is to contain the food, protect it from outside influences and damage, and provide consumers with information on ingredients and nutritional value. ${ }^{1}$ Most of the polymers used in industry are petroleum-based and present serious environmental issues due to their non-biodegradability. An alternative could be poly(lactide) (PLA), a biobased and biodegradable polymer produced from annually renewable resources, such as sugar beet or corn starch. PLA is currently the most used bioplastic in short-term applications in the food packaging sector. ${ }^{2,3}$
PLA is easy to process, presents high transparency and has adapted mechanical properties for rigid food packaging applications, but it is brittle at room temperature. To increase its ductility for film applications, plasticizing is commonly used. ${ }^{4}$ PLA has poor light and moderate oxygen barrier properties, which even decrease in case of utilization of plasticizers. ${ }^{5}$ This restricts its commercial application in the food packaging sector. ${ }^{6}$ The product shelf life of lipid-rich foods and bioactive compounds is highly dependent on their oxidative stability. Photo-oxidation reactions are therefore a real concern to the food industry, leading to the degradation of vitamins and bioactive compounds, to the development of rancidity in fatty food products, and hence to the decrease in nutritional and organoleptic quality of food products. $^{7,8}$ Since the amount of energy carried by light 
beams is inversely proportional to their wavelength, UV light possess more energy than visible light, inducing a higher rate of photochemical oxidation processes. ${ }^{9,10}$ Considering the increasing demand for production of healthier food products including vitamins and bioactive compounds, the use of packaging materials which protect these substances from photo-oxidative damage should be a priority.

Stabilization against photo-oxidative degradation of food can be achieved by UV-shielding. To that purpose, technological additives are often included in the polymer formulation. The UV blockers/absorbers act as a protection the polymer itself from photo-oxidative degradation, but also protect the product from UV light. Commonly used UV blockers include benzophenone and its derivatives, benzotriazoles, oxamide, and alfa-cyanocrylate. ${ }^{11,12}$ Such agents show excellent light barrier performances; however, there is a concern related to their migration from packaging to food products and their adverse effects on human health. ${ }^{11,13}$ These molecules are mostly petrochemicals, and their ecological impact is not well studied. In this sense, the use of natural antioxidants with UVVis absorbing properties could be a simple alternative for the fabrication of light barrier materials, and their migration from the polymer to food could avoid in addition oxidative reactions, extending the shelf life of perishable goods by active packaging.

Bixin, the main carotenoid present in annatto seeds (Bixa Orellana L), is a natural coloring agent with antioxidant properties that could be explored for its light absorbing character in packaging materials. Annatto extracts are allowed as food additive in the European Union and elsewhere and are currently used for the coloring of many commodity food products. ${ }^{14}$ Studies about its application in packaging materials are still scarce. In previous studies of our group, bixinrich extracts were used as a coloring and antioxidant additive in cast PLA films. Bixin was shown to be stable in the PLA matrix after film obtention, endowing films with light barrier properties and protecting sunflower oil from oxidation reactions. ${ }^{15,16}$ When introduced into poly(hydroxy butyrate) films, annatto extracts protected the polymer against thermal degradation and erosion caused by light. ${ }^{17}$

Common industrial melt processing technologies for the fabrication of food packaging require the use of temperatures higher than the melting point of the polymer. Processing temperatures of PLA extend typically between 160 and $220^{\circ} \mathrm{C}$. They are a function of the formulation and the presence or not of crystals. Therefore, the thermal stability of natural colorants and antioxidants at processing temperature needs to be evaluated.

This study aimed to produce active PLA packaging films with increased light barrier properties through the use of different concentrations of bixin and to evaluate the impact of heat treatment on their functional properties. The plasticizer acetyl tributyl citrate (ATBC) was chosen to produce ductile films because it was a widely used in PLA. ${ }^{418}$ The efficiency of ATBC to decrease the glass transition temperature and improve the mechanical properties of PLA were shown. ${ }^{4,18}$ In addition, ATBC is approved for use in food contact materials by the US Food and Drug Administration. ${ }^{719}$ It was already used in the formulation of antioxidant ${ }^{20}$ and antimicrobial ${ }^{21,22}$ PLA films, where ATBC proved its efficiency in increasing the ductility of PLA. Furthermore, ATBC favored the dispersion of antioxidant imine-based covalent organic frameworks, ${ }^{20}$ and synergistic plasticizing effects with antioxidant molecules, such as carvacrol or thymol could be observed. ${ }^{21}$ Here, the thermal stability of bixin and its migration to a food simulant was evaluated, using films which were hot-pressed after casting to mimic the heat damage caused during polymers processing.

\section{2 | EXPERIMENTAL}

\section{1 | Materials}

Polylactide (PLA) of extrusion grade "PLE001" containing at least $96 \%$ L-lactic acid was supplied from the NaturePlast (France). According to its technical data sheet, it melts between 155 and $160^{\circ} \mathrm{C}$ and degrades at $220^{\circ} \mathrm{C}$, with a density of $1.24 \mathrm{~g} / \mathrm{cm}^{3}$. Acetyl tributyl citrate (ATBC) was supplied by the Sigma-Aldrich (France). Annatto seeds were acquired from the Ivory Coast. All chemicals used were of analytical grade. The chemical structures of the different substances are shown in Figure 1.
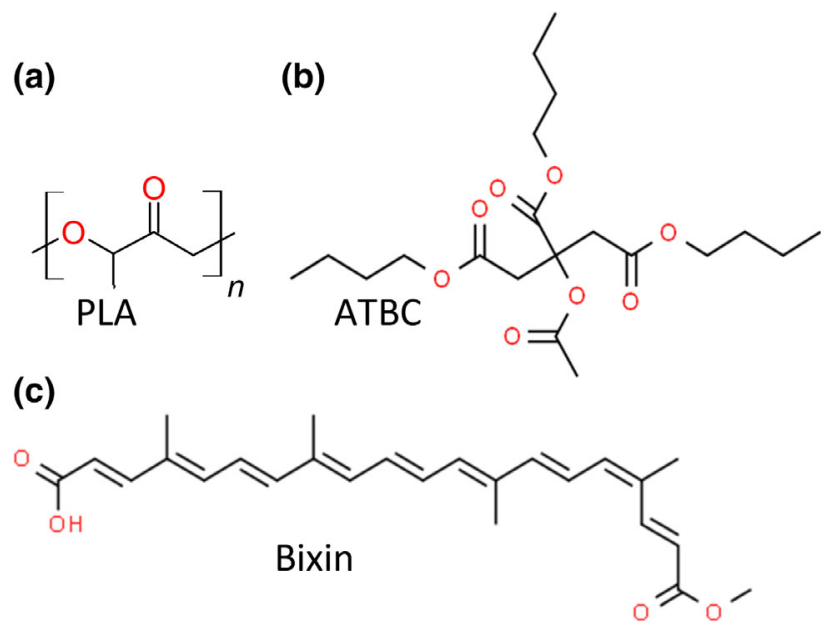

FI G U RE 1 Chemical structures of (a) acetyl tributyl citrate (ATBC); (b) poly(lactide) (PLA), and (c) bixin [Color figure can be viewed at wileyonlinelibrary.com] 


\section{2 | Bixin extraction}

Annatto seeds were washed with hexane and methanol, and bixin was extracted from the seeds by mechanical stirring with dichloromethane for $30 \mathrm{~min}$, at ambient temperature and protection from light. The purity of bixin extracts (>97\%) was checked as described elsewhere. ${ }^{15}$ The bixin quantity in the extract was measured with a UV-VIS spectrophotometer (Jasco V-750, Japan) at $\lambda_{\max }=470 \mathrm{~nm}$ in quartz cells using dichloromethane as a blank. The concentration of bixin was calculated by using its specific extinction coefficient according to the following formula:

$$
\operatorname{Bixin} \text { content }(\mu \mathrm{g} / \mathrm{g})=\frac{A \times V(\mathrm{ml}) \times 10^{4}}{A_{1 \mathrm{~cm}}^{1 \%}}
$$

where $\mathrm{A}$ is absorbance; $\mathrm{V}$ is total volume; $A_{1 \mathrm{~cm}}^{1 \%}=2826$ (bixin extinction coefficient in dichloromethane). ${ }^{23}$

\section{3 | Film production}

PLA pellets were dried at $80^{\circ} \mathrm{C}$ for $6 \mathrm{~h}$ under vacuum to remove residual moisture. PLA was dissolved in dichloromethane $(5 \% \mathrm{wt} / \mathrm{vol})$ by mechanical stirring at ambient temperature. Subsequently to the polymer dissolution, the plasticizer ATBC and the bixin extract were poured in the PLA solutions, achieving an ATBC concentration of $0.13 \mathrm{~g} / \mathrm{g}$ and bixin concentrations of $0.01,0.05$, and $0.1 \mathrm{mg} / \mathrm{g}$; the mass related to the sum PLA and ATBC total content (i.e., $1 \mathrm{~g}$ PLA/ATBC $+0.01 \mathrm{mg}$ bixin). The solutions were stirred for $10 \mathrm{~min}$ and then poured into Teflon recipients at a leveled surface. After solvent evaporation, the casted films were peeled and placed in an oven with forced air circulation at $40^{\circ} \mathrm{C}$ for $6 \mathrm{~h}$. In the following, the sample nomenclature informs on the composition of the PLA film: FP names the film of PLA without formulation, F1 the film with $0.01 \mathrm{mg} / \mathrm{g}$ bixin, F5 with $0.05 \mathrm{mg} / \mathrm{g}$ bixin, and F10 the film with $0.1 \mathrm{mg} / \mathrm{g}$ bixin. The formulations containing ATBC are labeled as follows: FPA means the PLA film with ATBC, FA1 the film with $0.01 \mathrm{mg} / \mathrm{g}$ bixin and $13 \mathrm{wt} \%$ ATBC, FA5 the film with $0.05 \mathrm{mg} / \mathrm{g}$ bixin and $13 \mathrm{wt} \%$ ATBC, and FA10 the film with $0.1 \mathrm{mg} / \mathrm{g}$ bixin and $13 \mathrm{wt} \%$ ATBC.

In order evaluate the bixin thermal stability when exposed to polymer melt processing temperatures, the cast films were pressed thanks to a heating press (Scamex, France) at $160^{\circ} \mathrm{C}$ during 4 and $6 \mathrm{~min}$. For that, film samples were placed between two Teflon sheets and two steel plates. The time of the heat-treatment included the melting and hot-pressing time, that is, 4 min of heat treatment meant 2 min without pressure followed by 2 min with a pressure of 5 tons. Films heat-treated during 6 min were kept in the press for 4 min without pressure and $2 \mathrm{~min}$ at a pressure of 5 tons. Afterwards, the press was quickly opened, and films were quenched at room temperature at a cold surface. Films were stored in desiccators protected from light, at room temperature.

\subsection{Bixin quantification in PLA films}

The bixin content of cast and thermally treated PLA films was evaluated by dissolving the films in dichloromethane with the aid of an ultrasonic bath. ${ }^{15}$ The bixin quantification was performed in quartz cells in a UV-VIS spectrophotometer (Jasco V-750, Japan) in dichloromethane: $\lambda_{\max }\left(A_{1 \%}\right)=470 \mathrm{~nm}$ (extinction coefficient 2826). The results were expressed as total bixin equivalent. Each analysis was repeated three times.

\section{5 | Thermal analysis (DSC)}

The analysis of the glass transition temperature $\left(T_{\mathrm{g}}\right)$ and the crystallinity degree $\left(X_{\mathrm{c}}\right)$ of the film samples were carried out using a Q100 DSC (TA Instruments), equipped with an intercooler. Calibration was performed with the help of an Indium standard. The purge $\mathrm{N}_{2}$ gas flow was $50 \mathrm{ml} / \mathrm{min}$. Samples $\left(3-5 \mathrm{mg}\right.$, loaded in TZero ${ }^{\mathrm{TM}}$ aluminum crucibles) were heated with a heat-cool-heat cycle at a constant heating rate of $10^{\circ} \mathrm{C} / \mathrm{min}$ from 10 to $180^{\circ} \mathrm{C}$. The degree of crystallinity $\left(X_{\mathrm{c}}\right)$ of the films was calculated using the enthalpy peaks from the second heating run, through the following equation:

$$
X c=\frac{\Delta H_{\mathrm{m}-} \Delta H_{\mathrm{cc}}}{\Delta H_{\mathrm{f}}(1-x)} \times 100
$$

where $\Delta H_{\mathrm{m}}$ is the enthalpy of melting, $\Delta H_{\mathrm{cc}}$ is the enthalpy of cold crystallization, $\Delta H_{\mathrm{f}}$ is the heat of fusion of $100 \%$ crystalline PLA $(93.7 \mathrm{~J} / \mathrm{g})$, and $x$ is the fraction sum of plasticizer and carotenoids in the films.

\section{6 | Mechanical properties}

A texture analyzer (TA.XT2ie Stable Micro Systems, UK) was used to the percentage of elongation at break (E). Thickness heterogeneity of films lead to uncertainty in the determination of the yield stress; therefore, it was not considered. Analyses were performed at $25^{\circ} \mathrm{C}$ with a load cell of $5 \mathrm{~kg}$ and an A/TGT self-tightening roller grips fixture. Ten replications were run for each test sample, 
where the strips were mounted individually between the grips of the equipment with an initial grip separation of $50 \mathrm{~mm}$ and a test speed of $0.8 \mathrm{~mm} / \mathrm{s}$. Parameters were obtained from stress-strain curves from uniaxial tensile tests and were calculated according to the ASTM D882 standard method.

\section{7 | Oxygen barrier properties}

The barrier properties of films to oxygen were determined using a manometric method on a permeability testing apparatus (GDP-C permeameter, Brugger Feinmechanik GmbH, Munich, Germany), working at $23^{\circ} \mathrm{C}$. The gas permeation system was initially outgassed under vacuum for $15 \mathrm{~h}$, then an $\mathrm{O}_{2}$ flow of $50 \mathrm{ml} / \mathrm{min}$ started on one side of the film sample. The pressure increase in the downstream compartment was recorded over time, and Permeability $(P)$ was determined from the steady state. The sorption $(S)$ and diffusion $(D)$ coefficients were calculated with the help of the time-lag method. The time-lag was obtained by calculating the intercept on the abscissa of the cumulated flux curve. $D$ was found by its relationship with $t_{\text {lag }}$ (Equation3) and $S$ was obtained with its correlation with $P$ and $D$ (Equation 34). The film thickness $(L)$ was measured in at least 5 random points with a Digimatic micrometer (Mitutoyo, Japan).

$$
\begin{aligned}
& t_{\text {lag }}=\frac{L^{2}}{6 D} \\
& P=D \times S
\end{aligned}
$$

\section{8 | Light transmittance of PLA films}

The barrier properties of the films to ultraviolet (UV) and visible light was evaluated using a UV-VIS spectrophotometer (Jasco V-750, Japan). The percentage of light transmittance through the films was measured in triplicate at selected wavelengths from 200 to $800 \mathrm{~nm}$. An empty quartz test cell was used as control.

\section{9 | Color analysis}

The film color was evaluated with a colorimeter (Hunter Lab system, model Miniscan XE) using the CIELab color parameters $L^{*}$ (luminosity), $a^{*}$ (red-green), and $b^{*}$ (yellow-blue). The films $(4 \mathrm{~cm} \times 4 \mathrm{~cm})$ were placed over a white disk $\left(L^{*}, 97.45 ; a^{*}, 5.23\right.$; and $\left.b^{*},-3.68\right)$, which was used as a white standard. The measurements were performed in triplicate in three different parts of the film surfaces. The Chroma value was calculated through Equation (45), and $\Delta$ Chroma was obtained by the difference between the parameter of cast and heat treated (HT) films (Equation 56). The total color differences $(\Delta \mathrm{E})$ between the HT and the cast films was calculated using Equation (67). The differences in $a^{*}$ and $b^{*}$ were calculated after Equations (78) and (89).

$$
\begin{gathered}
\text { Chroma }=\sqrt{a^{* 2}+b^{* 2}} \\
\Delta \text { Chroma }=\text { Chroma }_{\mathrm{HT}}-\text { Chroma }_{\text {cast }} \\
\Delta E=\sqrt{\left(L_{H T}^{*}-L_{\text {cast }}^{*}\right)^{2}+\left(a_{H T}^{*}-a_{\text {cast }}^{*}\right)^{2}+\left(b_{H T}^{*}-b_{\text {cast }}^{*}\right)^{2}} \\
\Delta a^{*}=a_{H T}^{*}-a_{\text {cast }}^{*} \\
\Delta b^{*}=b_{H T}^{*}-b_{\text {cast }}^{*}
\end{gathered}
$$

\subsection{0 | Bixin release kinetics}

The kinetic of bixin release from films to a fatty food simulant was evaluated following the methodology of our previous study. ${ }^{16}$ Ethanol 95\% (vol/vol), approved as a fatty food simulant substitute by the European Regulation No 10/2011 was used as a simulant. For that, $20 \mathrm{mg}\left(\sim 1 \mathrm{~cm}^{2}\right)$ of film was immersed in $6 \mathrm{ml}$ of ethanol 95\% (vol/vol) contained in $12 \mathrm{ml}$ amber flasks. The flasks were sealed with plastic caps and stored at $40^{\circ} \mathrm{C}$ for 65 days in the dark. The flasks were shaken regularly to minimize mass transfer resistance. The concentration of bixin $(C)$ was periodically determined by spectrophotometry (UV-VIS Jasco V-750, Japan) at $\lambda=457 \mathrm{~nm}$, and tests were interrupted when bixin concentration in food simulant was steady $\left(C_{\mathrm{eq}}\right)$. The simulant aliquots were returned to flasks after the analyses. A calibration curve of bixin in ethanol $95 \%$ was constructed from 0.3 to $5.3 \mu \mathrm{g} / \mathrm{ml}\left(\mathrm{R}^{2}=0.996\right)$. It is provided in the supporting information (Data S1). The limits of detection (LOD) and quantification (LOQ) were 0.002 and $0.008 \mu \mathrm{g} / \mathrm{ml}$, respectively. The LOD and LOQ were calculated following the methodology of the International Conference on Harmonization (2005). ${ }^{24}$

To evaluate the overall mass transfer resistance $(K)$ of bixin from the films to the liquid, a mass balance was used taking into account bixin degradation in the food simulant, as shown in Equation (10). 


$$
\frac{d C}{d t}=K \frac{A}{V}\left(C^{*}-C\right)-k_{\mathrm{d}} C, \frac{\mathrm{dC}}{\mathrm{dt}}=\mathrm{K} \frac{\mathrm{A}}{\mathrm{V}}\left(\mathrm{C}^{*}-\mathrm{C}\right)-\mathrm{k}_{\mathrm{d}} \mathrm{C}
$$

where $C$ is the bixin concentration in the food simulant $(\mu \mathrm{g} / \mathrm{ml}), K$ is the overall mass transfer coefficient $(\mathrm{m} / \mathrm{s}), A$ is the surface area of the film considering the migration occurs on both sides $\left(0.0002 \mathrm{~m}^{2}\right), V$ is the volume of the food simulant solution $\left(6 \times 10^{-4} \mathrm{~m}^{3}\right), C^{*} \mathrm{C}^{*}$ is the bixin concentration $(\mu \mathrm{g} / \mathrm{ml})$ in the inner part of the film and $k_{d}$ is the first-order kinetic degradation coefficient of bixin in ethanol $95 \%$ at $40{ }^{\circ} \mathrm{C}\left(2.155 \mathrm{~s}^{-1} \times 10^{-7}\right){ }^{16}$

As described in our previous work, $K$ takes into account the sum of diffusion mass resistances inside the polymeric film structure, the migration through the filmfood simulant interface, and the mass transfer of the migrant into the food simulant. ${ }^{16}$ The parameter $K \mathrm{~K}$ was obtained using the experimental data $C$ through the software EMSO (Environment for Modeling, Simulation and Optimization). Each kinetics was recorded in triplicate.

\section{3 | RESULTS AND DISCUSSION}

\section{1 | Functional properties of PLA/bixin and PLA/ATBC/bixin films after heat treatment}

\subsection{1 | Glass transition and mechanical properties of heat-treated PLA/bixin films}

The thermal and mechanical properties of the different PLA blends (Table 1) were analyzed in the aim to study the impact of the plasticizer, bixin and heat treatment on the film properties. ATBC is a widely used plasticizer for PLA. ${ }^{4}$ The solubility limit of PLA and ATBC was reported to afford between 50 and $60 \mathrm{wt} \%$ ATBC. ${ }^{25} \mathrm{Up}$ to this value, the $T_{\mathrm{g}}$ depression of PLA caused by the addition of ATBC can be modeled by the Fox model, above the value a distinct glass transition corresponding to ATBC can be observed. ${ }^{25}$ The concentration of $13 \%$ ATBC used in this work was chosen in accordance with literature ${ }^{4,5}$ as being the minimum concentration to yield the brittle to ductile transition of PLA. At this concentration the $T_{\mathrm{g}}$ of PLA is shifted below $40^{\circ} \mathrm{C}$. At this temperature the glass transition region extends near the mechanical testing temperature, hence PLA has a ductile behavior at room temperature. ${ }^{4,5}$ The addition of bixin to the films had no impact on the $T_{\mathrm{g}}$ of neat or plasticized PLA. Bixin could be easily mixed with ATBC. In an industrial extrusion process, the introduction of bixin in PLA could be facilitated using ATBC as a vector. The thermal treatment of the films caused an increase in $T_{\mathrm{g}}$ (Table 1), which can be attributed the loss of residual solvent from the casting process. Indeed, dichloromethane has a very strong plasticizing effect on $\mathrm{PLA}^{26}$ and very rigorous drying and heating is needed to evaporate it. The $T_{\mathrm{g}}$ value of the heat-treated films without ATBC corresponded to the literature values ${ }^{27}$ and the one of the PLA specification sheet of the fabricant. The $T_{\mathrm{g}}$ and the elongation at break values of PLA and PLA/ATBC were also coherent with literature. ${ }^{4,5,18}$ All PLA films were amorphous (crystallinity degree $<3 \%$ ) (Table 1 ). The addition of bixin had no impact on the $T_{\mathrm{g}}$ of PLA after heat treatment, while the elongation at break decreased with increasing bixin content. The highest concentration of carotenoid $(0.1 \%)$ anticipated films disruption in the presence of ATBC, significantly reducing the elongation at break for F10A. A

T A B L E 1 Thermal properties of cast and heat-treated (HT) films and mechanical properties of HT films

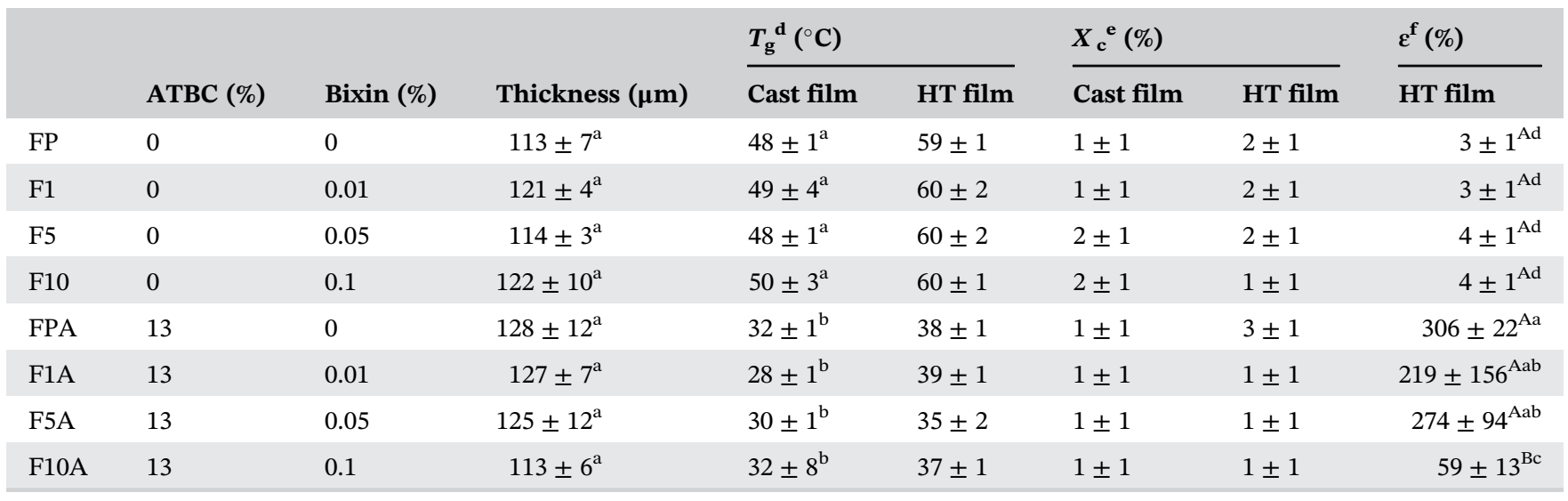

Note: "a,b,c, Different lowercase letters in the same column indicate significant differences $(p<0.05)$ among the 8 film formulations. "A,B,C” Different uppercase letters in the same column indicate significant differences $(p<0.05)$ between formulations of each group: Films without acetyl tributyl citrate (ATBC) and films with ATBC. All values are given as mean $\pm S D(n=3)$.

${ }^{\mathrm{d}} T_{\mathrm{g}}$ : glass transition temperature.

${ }^{\mathrm{e}} X_{\mathrm{c}}$ : crystallinity degree. HT, heat treatment $160^{\circ} \mathrm{C}-6 \mathrm{~min}$.

${ }^{\mathrm{f}} \varepsilon$ : elongation at break. 
hypothesis could be that at that concentration there might be some phase separation causing premature rupture.

\subsection{2 | Thermal stability of bixin during film processing}

The fabrication of plastic packaging involves thermal treatment of the materials during their processing. In the aim to produce packaging films with light barrier and antioxidant properties, the easiest procedure is to introduce the compounds in the polymer melt. The thermal stability of bixin at PLA extrusion temperatures and during different processing times was tested in simulated conditions by the means of a heating press. The Table 2 reports the degradation of bixin at $160^{\circ} \mathrm{C}$ over time.

The concentration of bixin in the cast PLA films was verified by quantification after dissolution of the cast PLA films in $\mathrm{CH}_{2} \mathrm{Cl}_{2}$ using UV-spectroscopy. It corresponded to the target value, except at the higher concentrations in the plasticized series, where some bixin was lost during film fabrication (Table 2). The degradation of bixin was substantial and, as expected, higher when the heat treatment time was increased (Table 2). Furthermore, it was more important in plasticized PLA. Heat, oxygen, and light are known to accelerate the oxidation and cis-/trans-isomerization of the highly unsaturated polyene chain of bixin. ${ }^{14}$ The main annatto coloring agent, 9-cis-bixin, undergoes a series of complex degradation reactions at temperatures above $70^{\circ} \mathrm{C}$ producing a range of products, including trans and other mono- and di-cis isomers of bixin. ${ }^{28,29}$ The degradation of bixin under high temperatures was reported, where almost $50 \%$ of bixin solubilized in vegetable oil was lost after exposure to $160^{\circ} \mathrm{C}$ for $2 \mathrm{~min}$. It was completely degraded after 2 min at $180^{\circ} \mathrm{C}^{30}$ However, only $23 \%$ of bixin loss was observed in biscuit dough baked at $150^{\circ} \mathrm{C}$ for $30 \mathrm{~min}$, showing that the matrix presents a considerable influence on the carotenoid stability. Many experiments about the encapsulation of carotenoids by polymers in the aim to enhance their thermal stability were already reported, and PLA is a widely used polymer in the field. ${ }^{31-33}$ Our system might produce an effect similar to matrix encapsulation, where the bioactive compound is uniformly distributed over the formed biopolymer carrier system. ${ }^{34}$ PLA might offer a protection towards oxygen and heat. The PLA/ATBC system is more fluid at a given temperature with higher oxygen solubility, which might be a reason for the higher bixin degradation in the plasticized matrix.

\subsection{3 | Color changes due to heat treatment}

The color attributes of the different samples are given in Table 3. PLA is a highly transparent polymer and this transparency was kept even if plasticized by ATBC. Bixin gave its typical yellow to red color to PLA. The color was more intense when the bixin concentration increased, with an important rise of the yellowness indicator $b^{*}$. The conjugated $\mathrm{C}=\mathrm{C}$ double bonds in the molecule serve as the light-absorbing chromophore. It is important to mention that at least seven conjugated double bonds are required for a carotenoid to have a perceptible color. ${ }^{35}$ The color stability of bixin is therefore strongly correlated with the stability of those conjugated double bonds. When bixin is heated, isomerization and degradation reactions occur producing a range of pale-yellow to orange products, where the temperature and the duration of the heating govern the red/yellow balance. ${ }^{29}$ The degradation of bixin due to the heat treatment of the films resulted in color changes, while there were no changes in neat PLA (Table 3).

T A B L E 2 Bixin content of casting films and bixin degradation after 4 and 6 min of heat treatment $(\mathrm{HT})$ at $160^{\circ} \mathrm{C}$

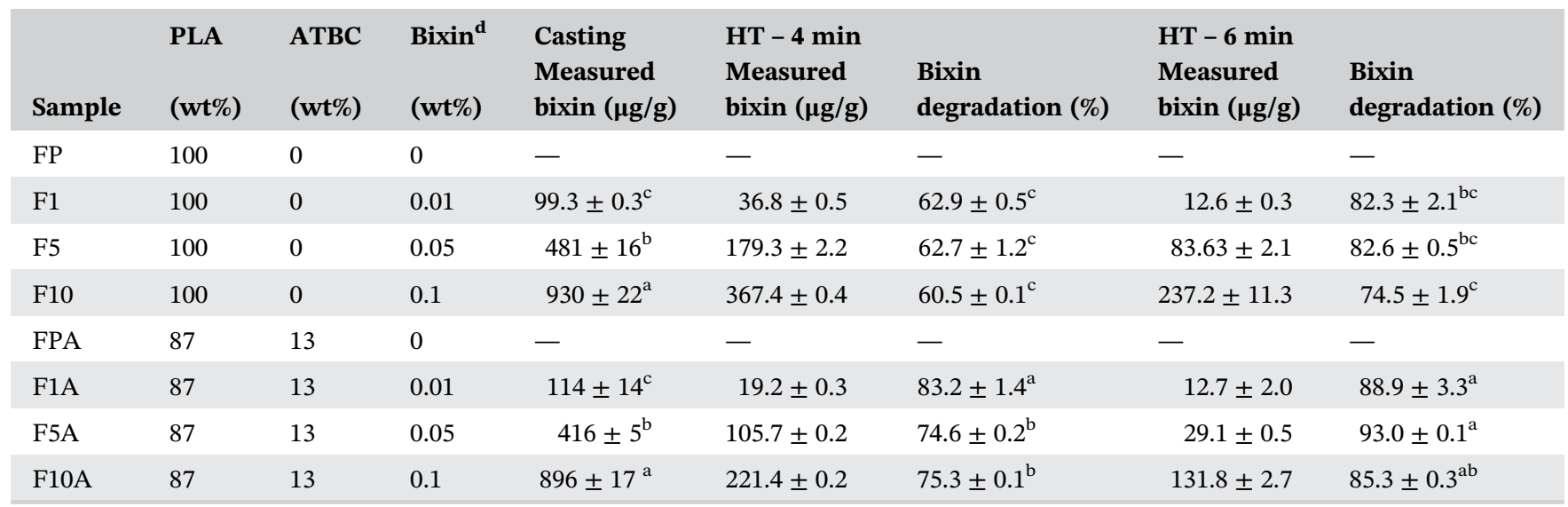

Note: “a,b,c" Different letters in the same column indicate significant differences $(p<0.05)$ among the films; results are given as mean $\pm S D(n=3)$.

${ }^{\mathrm{d} B i x i n}$ percentage based on the total content of poly(lactide) (PLA) and acetyl tributyl citrate (ATBC). 
The higher the concentration of bixin in the films, the lower were the color changes in $b^{*}$, Chroma, and total color differences (Table 3). The reduction in $b^{*}$ and $a^{*}$ values are related to the loss of yellowness and redness, respectively, while changes in Chroma are related to an alteration on color intensity. When bixin was added in lower concentrations, a significant decrease in film yellowness and color intensity was observed after thermal treatment, while the opposite was observed on formulations with $0.1 \%$ of bixin (F10 and F10A). Over $74 \%$ of bixin was degraded after 6 min of thermal treatment for the different film formulations (Table 2), where the final content of bixin in films ranged between $\sim 20 \mu \mathrm{g} / \mathrm{g}$ (F1 and F1A) and $200 \mu \mathrm{g} / \mathrm{g}$ (F10 and F10A). This result may explain the differences in their behavior concerning color changes: the higher the initial bixin content, the higher is the concentration of yellow degradation products responsible for an increase on yellow color intensity given by the increase in $b^{*}$ and Chroma. Chroma increased notably in F10 and F10A after thermal treatment. Our hypothesis is that the complete elimination of solvent turn films brighter and less opaque, and color intensity was increased when there was a higher concentration of colorants/bixin.

\section{2 | Functional properties of heat- treated PLA/ bixin films for food preservation}

\subsection{1 | Barrier properties and UV shielding}

The oxidative stabilization of food products can be achieved by exclusion of oxygen from the packaging, which removes the reaction partner. For that, the packaging polymer needs to feature adapted barrier properties to oxygen. Table 4 reports the oxygen permeability of the different heat-treated samples. The permeability values, diffusion, and solubility coefficients of PLA corresponded to the group of higher commonly reported values, ${ }^{36}$ which might be a result of the film preparation procedure by casting.

The presence of ATBC reduced the barrier properties of PLA because of the additional free volume inside the polymer. ${ }^{4,56}$ This phenomenon was largely described in literature and increased permeability of PLA/ATBC was already reported. ${ }^{5}$ The presence of bixin did not affect the oxygen barrier of PLA films, which is in agreement with the results found in our first study. ${ }^{15}$ PLA and plasticized PLA have intermediate oxygen barrier properties, approximately one order of magnitude higher than polystyrene and polyethylene and one order of magnitude lower than polyethylene terephthalate. ${ }^{2}$

The UV light absorption capacity of bixin is a very interesting feature for the development of food packaging materials with UV-shielding properties. The neat PLA films with or without ATBC were colorless and highly transparent to UV (280-400 nm) and visible light (400-800 nm), as shown in Figure 2. The blending of PLA or PLA/ATBC decreased only moderately the transmittance of visible light, despite of the strong and vibrant yellow-orange color of thermal treated films (Table 2). Figure 2 shows furthermore that the presence of bixin decreased strongly the light transmittance in the UV range. In Table 4 the quantification of the light transmittance at different wavelengths is reported. A substantial decrease of UVA (315-400 nm) and UVB (280-315 nm) light transmission was observed with increasing bixin content. The films formulated with $0.1 \%$ (F10) of bixin reached UVA transmission values below 10\% and UVB light transmittance below $15 \%$. The presence of ATBC

T A B L E 3 Visual color attributes, color parameters $L^{*}, a^{*}, b^{*}$, and Chroma of cast PLA and color changes $\left(\Delta a^{*}, \Delta b^{*}, \Delta E, \Delta\right.$ Chroma) after thermal treatment [Colour Table can be viewed at wileyonlinelibrary.com]

\begin{tabular}{|c|c|c|c|c|c|c|c|c|c|c|c|c|}
\hline \multicolumn{2}{|c|}{ АТВС (\%) } & \multirow{2}{*}{$\begin{array}{l}\text { Bixin (\%) } \\
0\end{array}$} & \multirow{2}{*}{ Cast film } & \multirow{2}{*}{$\mathbf{T P}^{\mathbf{a}}$ film } & \multirow{2}{*}{$\begin{array}{l}L^{*} \\
94.6\end{array}$} & \multirow{2}{*}{$\begin{array}{l}\boldsymbol{a}^{*} \\
-0.4\end{array}$} & \multirow{2}{*}{$\begin{aligned} & \boldsymbol{b}^{*} \\
& 2.4\end{aligned}$} & \multirow{2}{*}{$\begin{array}{c}\text { Chroma } \\
2.6\end{array}$} & \multirow{2}{*}{$\begin{array}{r}\Delta \boldsymbol{a}^{*} \\
0.1\end{array}$} & \multirow{2}{*}{$\begin{array}{r}\Delta \boldsymbol{b}^{*} \\
0.0\end{array}$} & \multirow{2}{*}{$\begin{array}{r}\Delta \boldsymbol{E} \\
0.2\end{array}$} & \multirow{2}{*}{$\begin{array}{c}\text { DChroma } \\
0.4\end{array}$} \\
\hline FP & 0 & & & & & & & & & & & \\
\hline FPA & 13 & 0 & & & 94.4 & -0.5 & 2.7 & 2.7 & 0.0 & 0.3 & 0.3 & 0.3 \\
\hline F1 & 0 & 0.01 & & & 93.0 & -4.0 & 19.2 & 20.0 & 2.6 & -43.8 & 43.8 & -43.4 \\
\hline F1A & 13 & 0.01 & & & 91.5 & -4.5 & 21.9 & 22.3 & 1.1 & -44.7 & 44.9 & -44.5 \\
\hline F5A & 13 & 0.05 & & & 88.2 & -7.5 & 70.8 & 72.3 & -9.3 & -34.7 & 35.2 & -33.3 \\
\hline F10 & 0 & 0.1 & & & 83.7 & 2.9 & 105.5 & 105.5 & -10.3 & 18.4 & 21.6 & 17.5 \\
\hline F10A & 13 & 0.1 & & & 84.9 & -1.5 & 103.0 & 103.0 & -11.0 & 13.7 & 18.2 & 13.2 \\
\hline
\end{tabular}

Abbreviations: ATBC, acetyl tributyl citrate; PLA, poly(lactide).

${ }^{\mathrm{a}} \mathrm{TP}$ : Heat treatment of cast films under the thermal press: $160^{\circ} \mathrm{C}, 6 \mathrm{~min}$. 
T A B L E 4 Oxygen barrier properties of PLA films and light transmittance at UV-B (300 nm), UV-A (380 nm), and visible (700 nm) light regions

\begin{tabular}{|c|c|c|c|c|c|c|c|c|}
\hline \multicolumn{2}{|c|}{ АТВС (\%) } & \multirow{2}{*}{$\begin{array}{l}\text { Bixin (\%) } \\
0\end{array}$} & \multirow{2}{*}{$\begin{array}{l}\mathbf{P}^{\mathbf{e}} \times \mathbf{1 0}^{\mathbf{1 8}} \\
\left(\mathbf{m}^{\mathbf{3}} \mathbf{\mathbf { m ~ m }} \mathbf{~}^{-\mathbf{2}} \mathbf{P a}^{-1} \mathbf{s}^{-1}\right) \\
3.31 \pm 0.30\end{array}$} & \multirow{2}{*}{$\begin{array}{l}D^{\mathbf{f}} \times 10^{12} \\
\left(\mathrm{~m}^{2} \mathbf{s}^{-1}\right) \\
3.3\end{array}$} & \multirow{2}{*}{$\begin{array}{l}\mathrm{S}^{\mathrm{g}} \times 10^{6} \\
\left(\mathrm{~m}^{3} \mathrm{~m}^{-3} \mathrm{~Pa}^{-1}\right) \\
1.0\end{array}$} & \multicolumn{3}{|c|}{ Light transmittance (\%) } \\
\hline $\mathrm{FP}$ & 0 & & & & & $\begin{array}{l}\text { UV-B } \\
63.1^{\mathrm{a}}\end{array}$ & $\begin{array}{l}\mathbf{U V}-\mathbf{A} \\
73.8^{\mathrm{a}}\end{array}$ & $\begin{array}{l}\text { VIS (700 nm) } \\
83.2^{\mathrm{a}}\end{array}$ \\
\hline FPA & 13 & 0 & $5.06 \pm 0.50$ & 4.9 & 1.0 & $60.2^{\mathrm{a}}$ & $73.0^{\mathrm{a}}$ & $80.8^{\mathrm{a}}$ \\
\hline $\mathrm{F} 1$ & 0 & 0.01 & $4.14 \pm 0.40$ & 3.5 & 1.2 & $58.2^{\mathrm{ab}}$ & $65.8^{\mathrm{b}}$ & $83.1^{\mathrm{a}}$ \\
\hline F5A & 13 & 0.05 & $5.08 \pm 0.50$ & 5.2 & 1.1 & $25.2^{d}$ & $23.5^{\mathrm{c}}$ & $80.5^{\mathrm{a}}$ \\
\hline F10 & 0 & 0.1 & $3.59 \pm 0.40$ & 3.2 & 1.1 & $10.0^{\mathrm{e}}$ & $4.4^{\mathrm{d}}$ & $64.8^{\mathrm{c}}$ \\
\hline F10A & 13 & 0.1 & $5.04 \pm 0.50$ & 4.2 & 1.2 & $14.9^{\mathrm{de}}$ & $9.5^{\mathrm{d}}$ & $77.5^{\mathrm{b}}$ \\
\hline
\end{tabular}

Note: “a,b,c,d” Different letters in the same column of the light transmission data indicate significant differences $(p<0.05)$ among the films.

Abbreviations: ATBC, acetyl tributyl citrate; PLA, poly(lactide).

${ }^{\text {e}} \mathrm{P}$ : Oxygen permeability.

${ }^{\mathrm{f}} \mathrm{D}$ : Oxygen diffusivity.

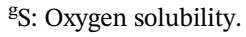

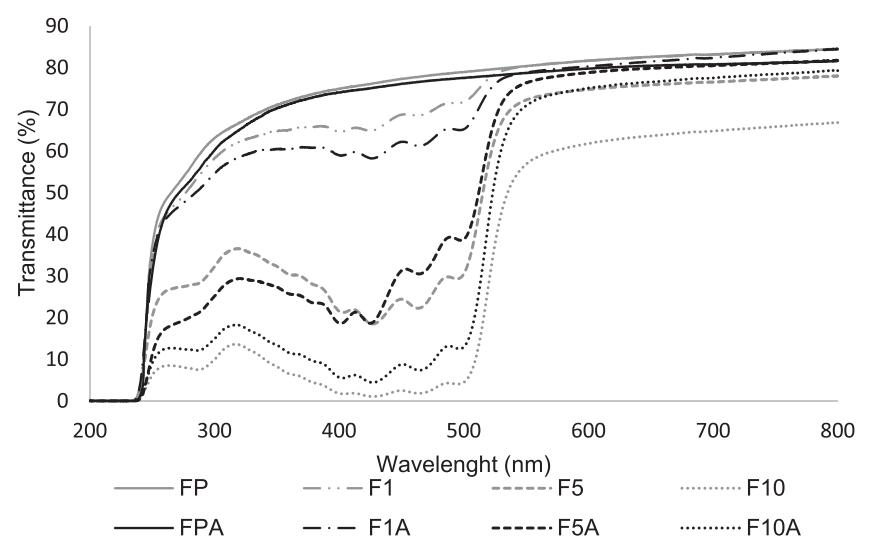

F I G U RE 2 Light transmittance (\%) spectra from 200 to $800 \mathrm{~nm}$ of heat-treated poly(lactide) (PLA) films blended with acetyl tributyl citrate (ATBC) and bixin. Films without ATBC: FP (0\% bixin); F1 (0.01\% bixin); F5 (0.05\% bixin); F10 (0.10\% bixin); films with ATBC: FPA (0\% bixin); F1A (0.01\% bixin); F5A (0.05\% bixin); F10A (0.10\% bixin)

in PLA films did not seem to alter the light transmission properties. We can conclude that bixin, even if it is partially degraded during heat treatment, could provide an interesting barrier against photo-degradation of packed foods, which could make it suitable for the fabrication of UVshielding food packaging by melt processing.

\subsection{2 | Bixin release from active films}

In our previous work, ${ }^{16}$ we showed that the release of bixin from semi-crystalline PLA films allowed the decrease of oxidation reactions in edible oil. However, the release rates were too slow for active protection of the oil at short times, that is, in the starting phase of the degradation. Therefore, an amorphous PLA was used because crystallites induce tortuosity to the diffusive pathway of molecules and decrease thereby transport rates. ${ }^{37}$ PLA was furthermore plasticized to speed up the release kinetics, because plasticizers increase free volume and increase mass transport kinetics. ${ }^{36}$ The relationship between PLA crystallinity and the release of active substances from polymeric matrices has been more frequently studied in the pharmaceutic field, where drugs release is shown to proceed faster in amorphous structures. ${ }^{38}$ Furthermore, the thermal degradation of bixin during the processing was taken into account. The release kinetics of bixin into a food simulant are shown in Figure 3 and the mass transport parameters, calculated with our previously developed model (Equation 9 10) are given in Table 5. The model fit was satisfying. In a previous study of our group, we added $0.01 \%$ of bixin in PLA films with a higher degree of crystallinity $\left(X_{\mathrm{c}}=22 \%\right)$. The migration rate of bixin to ethanol $95 \%$ (vol/vol) was $K=1.2 \times 10^{-8} \mathrm{~m} / \mathrm{s}^{15,16}$ The use of amorphous PLA allowed to speed up the release kinetics by a factor of approximately 5 for a same bixin content (sample F1 in Table 5) and by a factor of approximately 6 when plasticizing was used in addition (sample F1A in Table 5). The lower glass transition temperature of plasticized filmswhich ranged between 35 and $38^{\circ} \mathrm{C}$-implied that films were in a rubbery state at the temperature conditions of the migration test $\left(40^{\circ} \mathrm{C}\right)$, hence facilitating bixin release from the PLA matrix. ${ }^{36,39}$ 
F I G URE 3 Experimental data of bixin concentration (C) in ethanol 95\% and the curves of the kinetic model of bixin release from poly(lactide) (PLA) films (F1: 0.01\% bixin; F1A: 0.01\% bixin, $13 \%$ acetyl tributyl citrate [ATBC]; F5: 0.05\% bixin; F5A: 0.05\%, 13\% ATBC; F10: 0.1\% bixin; F10A: 0.1\% bixin, $13 \%$ ATBC)

T A B L E 5 Release kinetics of bixin from heat-treated PLA $\left(6 \mathrm{~min}-160^{\circ} \mathrm{C}\right)$ films blended or not with ATBC

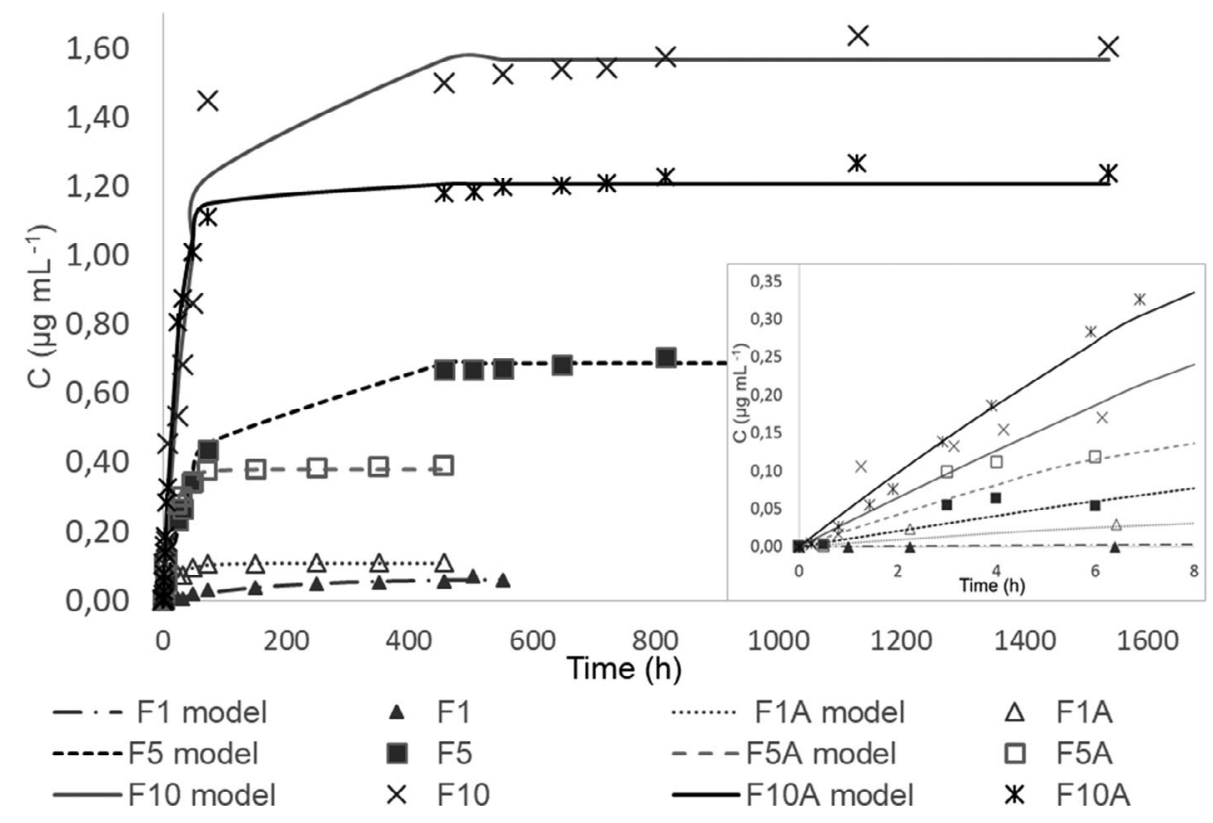

\begin{tabular}{|llllllll} 
& ATBC (\%) & Bixin $(\%)$ & $\begin{array}{l}\mathbf{K} \\
\left(\mathbf{m} / \mathbf{s} \times \mathbf{1 0}^{-7}\right)\end{array}$ & $\begin{array}{l}\boldsymbol{C}^{*} \\
(\boldsymbol{\mu g} / \mathbf{m l})\end{array}$ & $\mathbf{R}^{\mathbf{2}}$ & $\begin{array}{l}\boldsymbol{C}_{\mathbf{e q}} \\
(\boldsymbol{\mu g} / \mathbf{m l})\end{array}$ \\
\hline F1 & 0 & 0.01 & $0.5^{\mathrm{c}}$ & $0.07^{\mathrm{c}}$ & 0.96 & $0.08^{\mathrm{e}}$ \\
\hline F1A & 13 & 0.01 & $3.5^{\mathrm{a}}$ & $0.11^{\mathrm{c}}$ & 0.98 & $0.11^{\mathrm{e}}$ \\
\hline F5 & 0 & 0.05 & $1.3^{\mathrm{c}}$ & $0.69^{\mathrm{b}}$ & 0.96 & $0.72^{\mathrm{c}}$ \\
\hline F5A & 13 & 0.05 & $5.3^{\mathrm{a}}$ & $0.37^{\mathrm{bc}}$ & 0.98 & $0.39^{\mathrm{d}}$ \\
\hline F10 & 0 & 0.1 & $1.7^{\mathrm{bc}}$ & $1.63^{\mathrm{a}}$ & 0.98 & $1.60^{\mathrm{a}}$ \\
\hline F10A & 13 & 0.1 & $3.4^{\mathrm{ab}}$ & $1.23^{\mathrm{a}}$ & 0.99 & $1.24^{\mathrm{b}}$ \\
\hline
\end{tabular}

Note: “a,b,c,d,e” Different letters in the same column indicate significant differences $(p<0.05)$ among the films, K: Overall mass transfer coefficient $(\mathrm{K}), C^{*}$ : Adjusted apparent concentration fitted with the mathematical release model Equation (910), $C_{\text {eq }}$ : Bixin concentration in food simulant after reaching a pseudo-equilibrium.

Abbreviations: ATBC, acetyl tributyl citrate; PLA, poly(lactide)
The bixin concentration in PLA films did not affect its migration rate (Table 4). A pseudo-equilibrium concentration $\left(C_{\mathrm{eq}}\right)$ in the food simulant was reached after 150 and $600 \mathrm{~h}$ for films with and without ATBC, respectively (Figure 3). The decrease of the flow of bixin out of the polymer is most probably linked to the exhaustion of the polymer volume near the surface. At that moment, the internal transport resistance caused by the migration of bixin from the core of the material to the surface becomes preponderant. Using prediction of tools of the diffusion coefficient of bixin inside PLA, such as proposed by Fang et al. $^{40}$ or Baner et al. $^{41}$ and taking into account the data for other permeants summarized by Sonchaeng et al., ${ }^{36}$ the diffusion coefficient of bixin inside the PLA matrix would be lower than $10^{-16} \mathrm{~m}^{2} / \mathrm{s}$, which is much lower than the release kinetics. Furthermore, the long release times will most probably cause supplementary bixin degradation, which also decreases its concentration. Table 5 shows nevertheless interesting data concerning the actual release of bixin. Comparing films produced with the same bixin initial content, the differences found in $C_{\text {eq }}$ might be related to the higher bixin stability in the absence of ATBC. These differences were not observed for F1 and F1A, where the pseudoequilibrium concentration in the end of release test was statistically the same-probably due to low concentration of bixin, reducing the precision of its quantification. Considering that the degradation of bixin might occur in the films before and after its release to the media-inside and outside of the film matrix-the partition coefficient was not calculated and $C^{*}$ was used as an adjustable variable with no physical meaning. However, even though there was degradation of bixin during the heat treatment, the release kinetics into a food model were highly 
increased as compared to previous studies, which is positive for the stabilization of oxidation sensitive food.

\section{4 | CONCLUSIONS}

In this study, we analyzed the effect of heat treatment on active packaging films based on neat and plasticized PLA including bixin, a carotenoid of known antioxidant and UV shielding properties. The stability of bixin was higher in the absence of ATBC, where neat PLA had a positive influence on the carotenoid stability. Despite of the substantial loss of bixin caused by the thermal treatment, it was possible to produce transparent films with bright color and which endowed a satisfactory barrier to UVA and UVB transmission. The use of the plasticizer ATBC caused a decrease on the oxygen barrier properties of the films, but had a largely positive impact on the release kinetics of bixin to food simulants. The overall mass transfer coefficients were accelerated about 6 times. Applicative studies are underway to investigate the effect of this acceleration on the oxidative protection of food oils. As an additive for PLA, the bixin could allow its application on light-sensitive products packaging, extending their shelf life through the protection of food lipids, vitamins, and bioactive compounds from light exposure. Besides the UV protection, the release of bixin could avoid oxidation reactions in perishable goods.

\section{ACKNOWLEDGMENTS}

The research was supported by funds of the Doctoral Program Sandwich Abroad - CAPES PDSE Process Number 88881.189021/2018-01 and Fundação de Amparo à Pesquisa do Estado do Rio Grande do Sul (FAPERGS).

\section{ORCID}

Liana Stoll (1) https://orcid.org/0000-0002-9892-0352

Sandra Domenek (10) https://orcid.org/0000-0003-3012-

041X

Alessandro de Oliveira Rios (10 https://orcid.org/0000-

0001-8860-6928

\section{REFERENCES}

[1] R. Coles, D. McDowell, M. Kirwan, Food Packaging Technology, Blackwell Publishing Ltd., Oxford, England 2003.

[2] S. Domenek, S. Fernandes-Nassar, V. Ducruet, Adv. Polym. Sci. 2018, 279, 303.

[3] European Bioplastics. www.european-bioplastics.org (accessed: June 2020).

[4] A. Ruellan, V. Ducruet, S. Domenek, Chapter 5. in Poly(lactic acid) Science and Technology: Processing, Properties, Additives and Applications (Eds: A. Jiménez, M. Peltzer, R. A. Ruseckaite), The Royal Society of Chemistry, London, UK 2015, p. 124.
[5] C. Courgneau, S. Domenek, R. Lebosse, A. Guinault, L. Averous, V. Ducruet, Polym. Int. 2012, 61, 180.

[6] E. Castro-Aguirre, F. Iñiguez-Franco, H. Samsudin, X. Fang, R. Auras, Adv. Drug Deliv. Rev. 2016, 107, 333.

[7] S. E. Duncan, H.-H. Chang, Chapter 2. in Advances in Food and Nutrition Research (Ed: J. Henry 67, Academic Press, Amsterdam, Netherlands 2012, p. 25.

[8] I. Hrádková, R. Merkl, J. Šmidrkal, J. Kyselka, V. Filip, Eur. J. Lipid Sci. Technol. 2013, 115, 747.

[9] M. Narayanan, S. Loganathan, R. B. Valapa, S. Thomas, T. O. Varghese, Int. J. Biol. Macromol. 2017, 99, 37.

[10] R. P. Babu, K. O'Connor, R. Seeram, Prog. Biomater. 2013, $2,8$.

[11] X. Niu, Y. Liu, G. Fang, C. Huang, O. J. Rojas, H. Pan, Biomacromolecules 2018, 19, 4565.

[12] J. Pospíšil, S. Nešpůrek, in Plastic Packaging (Eds: O. G. Piringer, A. L. Baner), Wiley-VCH, Amsterdam, Netherlands 2008, p. 63.

[13] K. S. Anderson, K. M. Schreck, M. A. Hillmyer, Polym. Rev. 2008, 48, 85.

[14] M. Scotter, Food Addit. Contam. Part A 2009, 26, 1123.

[15] L. Stoll, R. Rech, S. H. Flôres, S. M. B. Nachtigall, A. de Oliveira Rios, J. Appl. Polym. Sci. 2018, 135, 46585.

[16] L. Stoll, R. Rech, S. H. Flôres, S. M. B. Nachtigall, A. de Oliveira Rios, Food Chem. 2019, 281, 213.

[17] C. S. Pagnan, A. C. Mottin, R. L. Oréfice, E. Ayres, J. J. D. Câmara, J. Polym. Environ. 2018, 26, 1169.

[18] A. Ruellan, A. Guinault, C. Sollogoub, V. Ducruet, S. Domenek, J. Appl. Polym. Sci. 2015, 132, 42476.

[19] M. Arrieta, P. L. Juan, F. Santiago, A. P. Mercedes, Acta Hortic. 2015, 1065, 719.

[20] P. Garcia-Arroyo, M. P. Arrieta, D. Garcia-Garcia, R. CuervoRodriguez, V. Fombuena, M. J. Mancheno, J. L. Segura, Polymer 2020, 196, 11.

[21] H. Celebi, E. Gunes, J. Appl. Polym. Sci. 2018, 135, 9.

[22] M. Rapa, L. M. Stefan, P. Preda, R. N. Darie-Nita, A. GasparPintiliescu, A. M. Seciu, C. Vasile, E. Matei, A. M. Predescu, Iran. Polym. J. 2019, 28, 271.

[23] J. F. Reith, J. W. Gielen, J. Food Sci. 1971, 36, 861.

[24] ICH (2005). Validation of analytical procedures: Text and methodology Q2 (R1). www.ema.europa.eu (accessed: November 2018)

[25] M. Baiardo, G. Frisoni, M. Scandola, M. Rimelen, D. Lips, K. Ruffieux, E. Wintermantel, J. Appl. Polym. Sci. 2003, 90, 1731.

[26] J.-W. Rhim, A. K. Mohanty, S. P. Singh, P. K. W. Ng, J. Appl. Polym. Sci. 2006, 101, 3736.

[27] M. Gerometta, J. R. Rocca-Smith, S. Domenek, T. Karbowiak, Reference Module in Food Science, Elsevier, Amsterdam, Netherlands 2019. https://doi.org/10.1016/B978-0-08-100596-5.22471-2.

[28] M. J. Scotter, L. Castle, G. P. Appleton, Food Chem. 2001, $74,365$.

[29] H. D. Preston, M. D. Rickard, Food Chem. 1980, 5, 47.

[30] P. G. Prabhakara Rao, T. Jyothirmayi, K. Balaswamy, A. Satyanarayana, D. G. Rao, LWT- Food Sci. Technol. 2005, 38, 779.

[31] C. Gimenez-Rota, I. Palazzo, M. R. Scognamiglio, A. Mainar, E. Reverchon, G. Della Porta, J. Supercrit. Fluids 2019, 146, 199.

[32] I. Marcet, S. Weng, S. Sáez-Orviz, M. Rendueles, M. Díaz, J. Food Eng. 2018, 239, 26.

[33] M. Roussaki, A. Gaitanarou, P. C. Diamanti, S. Vouyiouka, C. Papaspyrides, P. Kefalas, A. Detsi, Polym. Degrad. Stab. 2014, 108, 182. 
[34] C. Soukoulis, T. Bohn, Crit. Rev. Food Sci. Nutr. 2018, 58, 1.

[35] D. B. Rodriguez-Amaya, J. Food Compos. Anal. 2010, $23,726$.

[36] U. Sonchaeng, F. Iniguez-Franco, R. Auras, S. Selke, M. Rubino, L. T. Lim, Prog. Polym. Sci. 2018, 86, 85.

[37] A. S. Michaels, H. J. Bixler, J. Polym. Sci. A 1961, 50, 393.

[38] N. Kamaly, B. Yameen, J. Wu, O. C. Farokhzad, Chem. Rev. 2016, 116, 2602.

[39] P. Chalier, A. Ben Arfa, V. Guillard, N. Gontard, J. Agric. Food Chem. 2009, 57, 658.

[40] X. Y. Fang, S. Domenek, V. Ducruet, M. Refregiers, O. Vitrac, Macromolecules 2013, 46, 874.

[41] A. Baner, J. Brandsch, R. Franz, O. Piringer, Food Addit. Contam. 1996, 13, 587.

\section{SUPPORTING INFORMATION}

Additional supporting information may be found online in the Supporting Information section at the end of this article.

How to cite this article: Stoll L, Domenek S, Hickmann Flôres S, Nachtigall SMB, de Oliveira Rios A. Polylactide films produced with bixin and acetyl tributyl citrate: Functional properties for active packaging. J Appl Polym Sci. 2021;138:

e50302. https://doi.org/10.1002/app.50302 